\title{
Determinants of MRSA carriage/infection in health care workers in the Netherlands
}

\author{
M van Rijen", J Kluytmans, CAM-study Group \\ From International Conference on Prevention \& Infection Control (ICPIC 2011) \\ Geneva, Switzerland. 29 June - 2 July 2011
}

\section{Introduction / objectives}

Nosocomial transmission is considered to be the most important source for MRSA colonisation of health care workers $(\mathrm{HCW})$. However, the epidemiology is changing and community-acquired MRSA is increasing. The objective of this study was to investigate the determinants of MRSA carriage/infections in HCW in The Netherlands.

\section{Methods}

All newly identified HCW with MRSA in seventeen hospitals in the Netherlands were included from January 2009 until December 2010. MRSA determinant analysis was done based on the HCW's history combined with molecular typing results and then classified in risk groups described in the national infection prevention guidelines.

\section{Results}

In two years $68 \mathrm{HCW}$ were found to be MRSA positive for the first time. Analysis of risk factors revealed that $27.9 \%$ of the HCW ( $n=19)$ were considered to be caused by nosocomial transmission, $19.1 \%(n=13)$ had been exposed to pigs/veal calves, $10.3 \%(n=7)$ had worked in a foreign hospital, 1.5\% $(\mathrm{n}=1)$ were colonised due to transmission in a psychiatric home and $41.2 \%(n=28)$ could not be classified in a known risk group. Based on spa-typing, Livestock Associated MRSA (ST-398) was found in $100 \%$ of the HCW who had been exposed to pigs/veal calves $(n=13)$, in $16.7 \%$ of the HCW who had worked in a foreign hospital (1 positive, 5 negative, 1 unknown) and in $15.8 \%$ of the HCW who were colonised due to nosocomial transmission (3 positive, 16 negative) . Remarkably, $22.2 \%$ of the strains in the group

Laboratory for Microbiology and Infection Control, Amphia Hospital, Breda, Netherlands with unknown determinants belonged also to this clonal complex (6 positive, 21 negative, 1 unknown).

\section{Conclusion}

The majority $(\mathrm{n}=28)$ of newly identified MRSA positive $\mathrm{HCW}$ reported no known source. Strains with spa-types indicative for Livestock Associated MRSA were found in $18.9 \%$ of individuals who did not report contact to livestock. This indicates that LA-MRSA is spreading, in the community and/or in the hospital.

\section{Disclosure of interest}

None declared.

Published: 29 June 2011

doi:10.1186/1753-6561-5-S6-P12

Cite this article as: van Rijen et al:: Determinants of MRSA carriage/ infection in health care workers in the Netherlands. BMC Proceedings 2011 5(Suppl 6):P12.

Submit your next manuscript to BioMed Central and take full advantage of:

- Convenient online submission

- Thorough peer review

- No space constraints or color figure charges

- Immediate publication on acceptance

- Inclusion in PubMed, CAS, Scopus and Google Scholar

- Research which is freely available for redistribution 